Taking into account the quality of the relationship in HIV disclosure

Charlotte Smith, Department of Psychology, Anglia Ruskin University Rachel Cook, Department of Psychology, Anglia Ruskin University Poul Rohleder, School of Psychology, University of East London

Accepted 4 February 2016 for publication in AIDS \& Behavior

This article may not exactly replicate the final version published in the journal 


\title{
Taking into account the quality of the relationship in HIV disclosure
}

\begin{abstract}
Despite growing interest in HIV disclosure, most theoretical frameworks and empirical studies focus on individual and social factors affecting the process, leaving the contribution of interpersonal factors relatively unexplored. HIV transmission and disclosure often occur within a couple however, and this is where disclosure has the most scope as a HIV transmission intervention. With this in mind, this study explores whether perceived relationship quality influences HIV disclosure outcomes. Ninety-five UK individuals with HIV participated in a crosssectional survey. Retrospective data were collected on their perceived relationship quality prior to disclosing their HIV positive status, and on disclosure outcomes. Perceived relationship quality was found to significantly affect disclosure outcomes. Positive qualities in the relationship were associated with positive outcomes, whereas negative qualities were associated with negative outcomes. Results further confirmed that this association was not merely correlational, but demonstrated predictive power. Relationship quality might act as either a risk or a resilience factor in the disclosure process, and thus warrants greater attention in future research.
\end{abstract}

Key words: HIV/ AIDS; Disclosure; HIV transmission; relationship quality 


\section{Taking into account the quality of the relationship in HIV disclosure}

\section{INTRODUCTION}

The issue of HIV disclosure has received plenty of attention by researchers in the social and behavioral sciences [1]. As Flowers and Davies [2] observe, early studies tended to examine disclosure in terms of having a stigmatized identity and accessing social support, while more recent work has tended to focus on encouraging and promoting HIV disclosure as an important and necessary health behavior in HIV prevention. Indeed, disclosure, to intimate partners in particular, is associated with promising public health benefits primarily due to its strong, robust associations with safer sex practices (primarily condom use) and its links with prompt HIV testing and diagnosis (i.e. working as a primary and secondary prevention strategy) [3-4]. However, this primary emphasis on the public health benefits of HIV disclosure has meant that the effect of disclosure on HIV-positive individuals' wellbeing has not always been fully considered [5] and other positive outcomes of disclosure to the individual are not fully understood.

With improved medical treatment, most infected people are now living with HIV as a chronic illness, and attention has turned to investigating factors that promote good quality of life and wellbeing in people living with HIV, in addition to HIV prevention. As a result of improved treatment, HIV status disclosure now has to be negotiated many times, with different persons, throughout a normal lifespan [6]. This has resulted in an emerging interest in investigating the effects of disclosing at the personal level, for example by asking people living with HIV (PLWH) about the benefits of disclosure, and the negative consequences of disclosure, as informed by their personal experiences [7].

Although disclosure is primarily framed as a health behavior benefit, and a psychological and social benefit to the individual in terms of accessing social support [8] and increased adjustment 
to the virus [9], the various interpersonal implications of disclosure are not always examined in depth. Some people may experience negative consequences of disclosure such as damage to existing relationships [10], stigma and discrimination [11] as well as potential abuse [12-13]. Attention is thus often given to supporting people to disclose in spite of these potential negative consequences given the effect that HIV-status disclosure has on reducing HIV transmission risk overall, and thus safeguarding public health. A focus is often on rates of disclosure - has the individual disclosed or not - and factors related to disclosure decisions, but not necessarily on whether it is safe for the individual to do so [5]. Predominantly, research attention has been given to the effects of two factors on disclosure- the inhibitive effects of stigma on a disclosure occurrence, and the promotional effects of social support in terms of subsequent disclosure behavior.

A number of disclosure models have been developed in the literature to investigate the decisionmaking process that individuals go through in disclosing their HIV status to others. For example, Arnold and colleagues [14] have argued that determined rules regarding one's social identity and social role affect the likelihood of HIV disclosure. Context. To give an example (adapted from Arnold et al, 2008), in terms of disclosing within a friendship, an individual may possess the thought that "I shouldn't keep something so big from a friend because friends are supposed to tell eachother personal things" (i.e. social role cognition). An individual is proposed to simultaneously have a social identity cognition (e.g. "I am a person living with HIV and therefore it is my duty to increase people's knowledge of HIV". According to this model, these two together inform a determined 'disclosure rule' (or more simply, a disclosure decision) i.e. tell my friends (Arnold et al, 2008)' 
Bairan and colleagues [15] provide a model of HIV disclosure that describes when disclosure is likely to occur/ not occur, as a function of the relationship context (whether the relationship is sexual or non-sexual). According to this model, disclosure within a sexual relationship is likely to occur when the relationship is committed and long term and is significantly less likely to occur when the sexual relationship is casual and short term.

A more recent model that has received attention in the literature, the Disclosure Process Model [1], details the process of each instance of HIV disclosure. Briefly, the model proposes that disclosure occurs through three main phases: a decision making phase (where individuals make a decision to disclose in order to gain something, or in order to avoid something aversive; the disclosure event (comprising of the amount of information that is disclosed, and the reaction of the person being disclosed to); and finally a feedback loop, recognizing that disclosure is influenced by past HIV disclosure experiences. Throughout these three phases of disclosure, disclosure outcome is believed to be determined by the level of social support available to the discloser, the extent to which the disclosure is experienced as an emotional release and any relevant changes in the social environment during the process [16].

Examining disclosure within the framework of conceptual models is useful for public health promotion, but it suggests that disclosure amounts to cognitions and behaviors that can be understood and influenced through interventions to promote pro-health behaviors, and does not always take in to account the social and emotional complexity of disclosure [2]. The interpersonal context and quality of relationship in which disclosure takes place is not often elucidated beyond broad categorizations of the nature and length of relationship; for example whether it is a casual or committed relationship, the partner is anonymous or close, the relationship is short term or long term and unmarried or married [see for example 17-19]. However, many of the reasons that people 
have for not disclosing may revolve around qualities of their current relationship [for example, poor communication; 20]

This paper reports on a study, the aim of which was to investigate whether the quality of the relationship within an intimate partner context, is associated with disclosure outcomes. In particular, whether factors indicative of a poor quality relationship (such as the presence of emotional abuse) are associated with a poor disclosure outcome, and whether factors indicative of a positive quality relationship (such as a high level of relationship trust) are associated with a positive disclosure outcome.

Most disclosure studies define outcome in terms of whether disclosure happened or not. In line with the transformation of HIV into a chronic condition and the need to negotiate disclosure as a core part of psychologically adjusting to HIV, this research widens the definition of disclosure outcome to include the individual's feelings about their disclosure, their partner's reaction, and the effects on their relationship.

\section{METHOD}

\section{Design}

A mixed methods survey design was implemented within a cross-sectional study. The survey asked participants living with HIV who had reported disclosing to an intimate partner at some point in their life to recall this experience and then to answer queries related to it; it thus collected retrospective self-reported accounts. 


\section{Measures}

A survey questionnaire was developed for the purposes of this study. Questionnaire items were informed by a review of the disclosure literature and in consultation with a national HIV support organization based in London. The survey included items measuring perceptions of the nature of the relationship and different disclosure outcomes (immediate and longer-term outcomes) within the relationship context. A retrospective design was adopted, whereby the participants were asked to recall their most recent experience of disclosing to an intimate partner and to answer the questions based on their recall of this specific instance of disclosure. Table 1 details the factors being assessed and the corresponding items that were used to assess them. Responses were measured using a Likert Scale ranging from 1 to 5 with 1 representing strongly disagree and 5 representing strongly agree. A higher number represented the participant endorsing more strongly the particular (negative or positive) property of the relationship being assessed. For questions that leant themselves to a binary or categorical response, a yes or no option or a space for a response was provided (e.g. whether the disclosure was perceived as contributing towards a subsequent breakup). The questionnaire also included qualitative questions asking respondents to describe the process of disclosure (this qualitative data will be presented in a future publication).

The questions were piloted with 4 PLWH currently residing in the UK- consisting of 2 males and 2 females. Feedback from the survey was received via email. A consultation also took place with a HIV activist, who is also the CEO of a national HIV charity. Minor changes were made to the original phrasing of the items based on the feedback received. For example, the word 'disclosure' was rephrased as 'having told them [the partner] about your HIV' in some questions, where the term 'disclosure' was considered to be too clinical (see table 1). The survey was administered online using a survey website (Surveygizmo). Paper copies of the survey were also available upon request. 


\section{Participants}

The survey was advertised through the networks of 31 HIV-related organizations across the UK, using paper and electronic flyers which the organizations distributed through their email lists, and/or advertised on the their online forums and social media. The inclusion criteria were that respondents needed to be 18 years or older, currently living in the UK, living with HIV, and have disclosed an HIV positive status to an intimate partner at least once in their lifetime.

Recruitment occurred over a period of 10 months between February and November, 2013. In an effort to improve response rates, the survey was advertised in three main 'pushes' occurring in February, April and September. For each of these times, new charities were targeted and it was re-released by some of those already involved. 
Table 1: Items included in the survey questionnaire

\begin{tabular}{|c|c|c|c|c|}
\hline \multicolumn{2}{|c|}{$\begin{array}{l}\text { The level on which each } \\
\text { given variable is situated }\end{array}$} & Variable & Corresponding survey item & Method of assessment and scoring \\
\hline \multirow{5}{*}{\multicolumn{2}{|c|}{$\begin{array}{l}\text { Factors of the } \\
\text { relationship }\end{array}$}} & Level of trust in the relationship & $\begin{array}{l}\text { Before considering disclosing to my } \\
\text { partner, we were in a trusting } \\
\text { relationship }\end{array}$ & $\begin{array}{l}\text { Likert scale (1-5) with } 5 \text { representing a high level of } \\
\text { trust in the relationship and } 1 \text { representing a low level } \\
\text { of trust in the relationship }\end{array}$ \\
\hline & & $\begin{array}{l}\text { Degree to which the relationship } \\
\text { was committed }\end{array}$ & $\begin{array}{l}\text { Before considering disclosing to my } \\
\text { partner, my partner was committed to } \\
\text { me }\end{array}$ & $\begin{array}{l}\text { Likert scale (1-5) with } 5 \text { representing a high level of } \\
\text { commitment and } 1 \text { representing a low level of } \\
\text { commitment }\end{array}$ \\
\hline & & $\begin{array}{l}\text { Degree to which there were unequal } \\
\text { power relations in the relationship }\end{array}$ & $\begin{array}{l}\text { Before considering disclosing to my } \\
\text { partner, the partnership was unequal }\end{array}$ & $\begin{array}{l}\text { Likert scale }(1-5) \text { with } 5 \text { representing more unequal } \\
\text { power relations and } 1 \text { representing a lesser degree of } \\
\text { unequal power relations }\end{array}$ \\
\hline & & $\begin{array}{l}\text { Extent to which the relationship } \\
\text { was tumultuous }\end{array}$ & $\begin{array}{l}\text { Before the time that I considered } \\
\text { disclosure, we had experienced some } \\
\text { difficulties in the relationship }\end{array}$ & $\begin{array}{l}\text { Likert scale (1-5) with } 5 \text { representing a highly tumultuous } \\
\text { relationship and } 1 \text { representing a non-tumultuous } \\
\text { relationship }\end{array}$ \\
\hline & & $\begin{array}{l}\text { Extent to which emotional abuse } \\
\text { was an issue in the relationship }\end{array}$ & $\begin{array}{l}\text { Before the time that I considered } \\
\text { disclosure, I had been hurt by my } \\
\text { partner emotionally }\end{array}$ & $\begin{array}{l}\text { Likert scale (1-5) with } 5 \text { representing a bigger problem } \\
\text { of emotional abuse by the partner, and } 1 \text { representing an } \\
\text { absence of emotional abuse. }\end{array}$ \\
\hline \multirow[t]{5}{*}{$\begin{array}{l}\text { Disclosure } \\
\text { outcomes }\end{array}$} & \multirow[t]{2}{*}{$\begin{array}{l}\text { Individual } \\
\text { level }\end{array}$} & $\begin{array}{l}\text { Level of perceived psychological } \\
\text { safety immediately after disclosing } \\
\text { (individual level) }\end{array}$ & $\begin{array}{l}\text { I felt safe psychologically after having } \\
\text { disclosed my status }\end{array}$ & $\begin{array}{l}\text { Likert scale (1-5) with } 5 \text { representing a high feeling of } \\
\text { psychological safety and } 1 \text { representing a low feeling of } \\
\text { psychological safety. }\end{array}$ \\
\hline & & $\begin{array}{l}\text { Satisfaction with the disclosure } \\
\text { decision (individual) }\end{array}$ & $\begin{array}{l}\text { I was satisfied with my decision to } \\
\text { disclose to my partner }\end{array}$ & $\begin{array}{l}\text { Likert scale }(1-5) \text { with } 5 \text { representing higher satisfaction } \\
\text { with the decision and } 1 \text { representing a low degree of } \\
\text { satisfaction with the decision }\end{array}$ \\
\hline & $\begin{array}{l}\text { Partner } \\
\text { level }\end{array}$ & $\begin{array}{l}\text { Degree to which the partner reacted } \\
\text { positively (partner level) }\end{array}$ & $\begin{array}{l}\text { Overall, my partner reacted positively } \\
\text { to my disclosure }\end{array}$ & $\begin{array}{l}\text { Likert scale (1-5) with } 5 \text { representing a more positive } \\
\text { reaction from the partner and } 1 \text { representing a less } \\
\text { positive reaction from the partner }\end{array}$ \\
\hline & \multirow[t]{2}{*}{$\begin{array}{l}\text { Dyadic } \\
\text { level }\end{array}$} & $\begin{array}{l}\text { Degree to which emotional } \\
\text { closeness increased in the } \\
\text { relationship after disclosure (dyadic } \\
\text { level) }\end{array}$ & $\begin{array}{l}\text { After I disclosed my HIV we felt } \\
\text { closer as a couple }\end{array}$ & $\begin{array}{l}\text { Likert scale }(1-5) \text { with } 5 \text { representing a higher level of } \\
\text { emotional closeness and } 1 \text { representing less of a } \\
\text { presence of this effect of disclosure }\end{array}$ \\
\hline & & $\begin{array}{l}\text { Degree to which the couple argued } \\
\text { more after the disclosure than } \\
\text { before (dyadic level) }\end{array}$ & $\begin{array}{l}\text { After I disclosed my HIV we started } \\
\text { arguing more than before }\end{array}$ & $\begin{array}{l}\text { Likert scale (1-5) with } 5 \text { representing a high incidence } \\
\text { of arguing more following the disclosure and } 1 \\
\text { representing less of a presence of this effect of } \\
\text { disclosure. }\end{array}$ \\
\hline
\end{tabular}




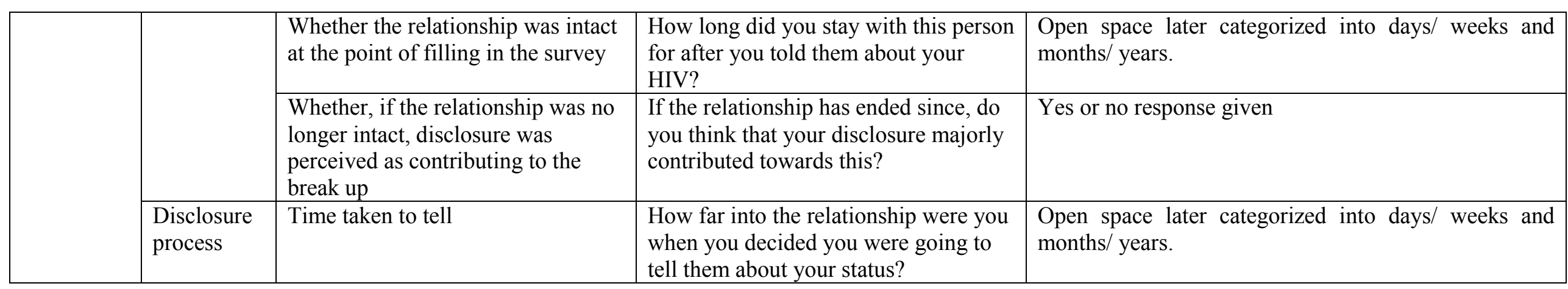


A total of 95 respondents completed the survey. Their sociodemographic characteristics are presented in Table 2. As table 2 shows, nearly half of the participants were diagnosed in the pre-HAART era $(42.86 \%)$, with the other half having received their diagnosis in the postHAART era.

Regarding the length of time since the last disclosure experience, currently being reported on, $3.53 \%$ were reporting on a disclosure that occurred in the last 12 months, $16.47 \%$ were reporting on a disclosure that occurred between 13 months to 2 years ago, $29.41 \%$ were reporting on a disclosure that had occurred between 25 months and 4 years, with the remainder reporting on a disclosure that occurred 4 years ago or more. 14.12 were reporting on a disclosure that had occurred between 4 and 6 years, with the remainder reporting on a disclosure that had occurred more than 6 years ago.

\section{Method of analysis}

The data were analyzed using correlations, tests of difference, and one stepwise regression analysis, in SPSS. The categorical data was analyzed using tests of difference. Data from individual 5 point Likert scales was treated as continuous, given that other assumptions (i.e. normality and equal variance) were met, and was analyzed using correlations. One stepwise regression analysis was conducted also on data that was continuous in order to explore whether a potential relationship between factors of the relationship and disclosure outcome were not only associated but predictive. It is important to note that the outcome of receiving a physically violent reaction from the partner following the disclosure was excluded from inferential based analyses due to the low variability in scores in this domain (see table 3). 


\begin{tabular}{|c|c|c|}
\hline \multicolumn{3}{|c|}{ Table 2: Sample Demographics $(\mathrm{N}=95)$} \\
\hline & $\mathrm{n}$ & $(\%)$ \\
\hline \multicolumn{3}{|l|}{ Gender } \\
\hline Male & 70 & $(73.68)$ \\
\hline Female & 25 & $(26.32)$ \\
\hline \multicolumn{3}{|l|}{ Age range } \\
\hline $18-24$ years & 2 & $(0.02)$ \\
\hline $25-34$ years & 21 & $(22.11)$ \\
\hline $35-49$ years & 41 & $(43.16)$ \\
\hline $50+$ years & 31 & $(32.63)$ \\
\hline \multicolumn{3}{|l|}{ Education } \\
\hline Secondary school & 15 & $(15.79)$ \\
\hline College/ sixth form & 27 & $(28.42)$ \\
\hline University & 53 & $(55.79)$ \\
\hline \multicolumn{3}{|l|}{ Relationship status } \\
\hline Single & 25 & $(26.32)$ \\
\hline Dating & 17 & $(17.90)$ \\
\hline Cohabiting & 24 & $(25.26)$ \\
\hline Married & 11 & $(11.58)$ \\
\hline Civil partnership & 9 & $(9.47)$ \\
\hline Separated & 3 & $(3.16)$ \\
\hline Divorced & 4 & $(4.21)$ \\
\hline Widowed & 2 & $(0.02)$ \\
\hline \multicolumn{3}{|l|}{ Sexual orientation } \\
\hline Gay male & 59 & $(62.1)$ \\
\hline Heterosexual male & 11 & $(11.58)$ \\
\hline Lesbian female & 2 & $(0.02)$ \\
\hline Heterosexual female & 22 & $(23.16)$ \\
\hline Bisexual female & 1 & $(1.05)$ \\
\hline \multicolumn{3}{|l|}{ Region in the UK } \\
\hline Yorkshire and The Humber & 1 & $(1.05)$ \\
\hline East Midlands & 5 & $(5.26)$ \\
\hline East of England & 9 & $(9.47)$ \\
\hline London & 30 & $(31.58)$ \\
\hline South Central England & 3 & $(3.16)$ \\
\hline South East Coast & 11 & $(11.58)$ \\
\hline South West of England & 11 & $(11.58)$ \\
\hline West Midlands & 3 & $(3.16)$ \\
\hline North West of England & 7 & $(7.37)$ \\
\hline Wales & 4 & $(4.21)$ \\
\hline Scotland & 10 & $(10.53)$ \\
\hline Channel Islands and Isle of Man & 1 & $(1.05)$ \\
\hline \multicolumn{3}{|l|}{ Ethnicity } \\
\hline White British & 69 & $(72.63)$ \\
\hline White Irish & 3 & $(3.16)$ \\
\hline White other & 5 & $(5.26)$ \\
\hline Mixed White and Black Caribbean & 1 & $(1.05)$ \\
\hline Mixed White and Asian & 1 & $(1.05)$ \\
\hline Mixed White and other & 1 & $(1.05)$ \\
\hline Black or Black British Caribbean & 4 & $(4.21)$ \\
\hline Black or British African & 9 & $(9.47)$ \\
\hline Black or Black British other & 1 & $(1.05)$ \\
\hline Other & 1 & $(1.05)$ \\
\hline \multicolumn{3}{|l|}{ Length of time since diagnosis* } \\
\hline$\leq 5$ years & 25 & $(27.47)$ \\
\hline $6-10$ years & 12 & (13.19) \\
\hline $11-15$ years & 15 & (16.48) \\
\hline $16-20$ years & 17 & (18.68) \\
\hline $21-25$ years & 10 & $(10.99)$ \\
\hline$\geq 26$ years & 12 & $(13.19)$ \\
\hline
\end{tabular}

* only 91 participants provided data for this question 
Due to the number of correlational analyses and tests of difference conducted (40), a Bonferroni correction was applied to these $(.05 / 40=.00125)$. Whilst this isn't always standard practice in exploratory research such as this, where a preliminary association between under-researched variables is the primary aim [e.g. 21] it was considered appropriate as a way of increasing the rigor of the research, through reducing the risk of type I error. Where this correction was applied, and the statistical test emerged as significant but did not remain so once the bonferroni correction applied, this was reported.

All correlations were one tailed (resulting in an adjusted alpha level of $p<.00125$ ). This is because it is posited here that factors indicating a good quality relationship will be associated with positive disclosure outcomes, and factors indicating a negative quality relationship will be associated with poor disclosure outcomes. Regarding the tests investigating relationship factors in long-term outcome, the chi-squared test, Yates' continuity correction, and Fisher's exact test were conducted where appropriate. Each test of difference was two-tailed (with an adjusted alpha level of $\mathrm{p}<.000625)$. This is because a proposed relationship between the nature of the relationship and disclosure outcomes is harder to predict. For example, taking the outcome of time taken to tell the partner- it is possible that a good quality relationship means that the individual feels able to carry out a disclosure more promptly, but equally it may mean that it takes longer to tell the partner because the individual is aware that they have more to lose.

Where the stepwise regression analysis was carried out, all necessary assumptions were screened for and/ or tested using guidelines provided by Field (2009) and Mayers (2013) [22, 23]. Specifically, non zero variance, perfect multicollinearity (which was not present), homoscedasticity, independent errors, linearity of the relationship, convariance ratio was 
screened for and/ or tested. Using criteria provided by the above authors, each of these assumptions was satisfactorily met.

In line with the recommendations of the APA [24], a power analysis was conducted prior to data collection. A power calculation for the regression analysis was conducted using the computer software $\mathrm{G}^{*}$ power [25]. Expecting a medium effect size (.15) with $80 \%$ power and an alpha level of .05 , a sample of 103 people was required. The final number of participants inputted into the stepwise regression analysis was 93 people. A posthoc power analysis however revealed that the final power achieved was $75 \%$. This is considered close enough to the desired 80\% (see Field, 2009) [24]. Guidelines provided by Clark-Carter (2004) [26] were drawn on to calculate the sample required for the correlational analyses. Clark-Carter (2004) state that for a Spearman's rho analysis that is expecting a medium effect size (.3), with $80 \%$ power and with an alpha level of .05 , a minimum sample size of 75 participants is needed. For the majority of correlational analyses (apart from where otherwise stated) the final minimum number of people inputted into each correlation analysis was 95 people. The analyses then were considered as having adequate statistical power to detect a real effect.

\section{RESULTS}

Both correlations and chi-square were used to test associations between factors of the relationship and disclosure outcomes (details in table 4). 
Table 3: Descriptive statistics (number in each group, with percentages in the parentheses) $(n=95)$

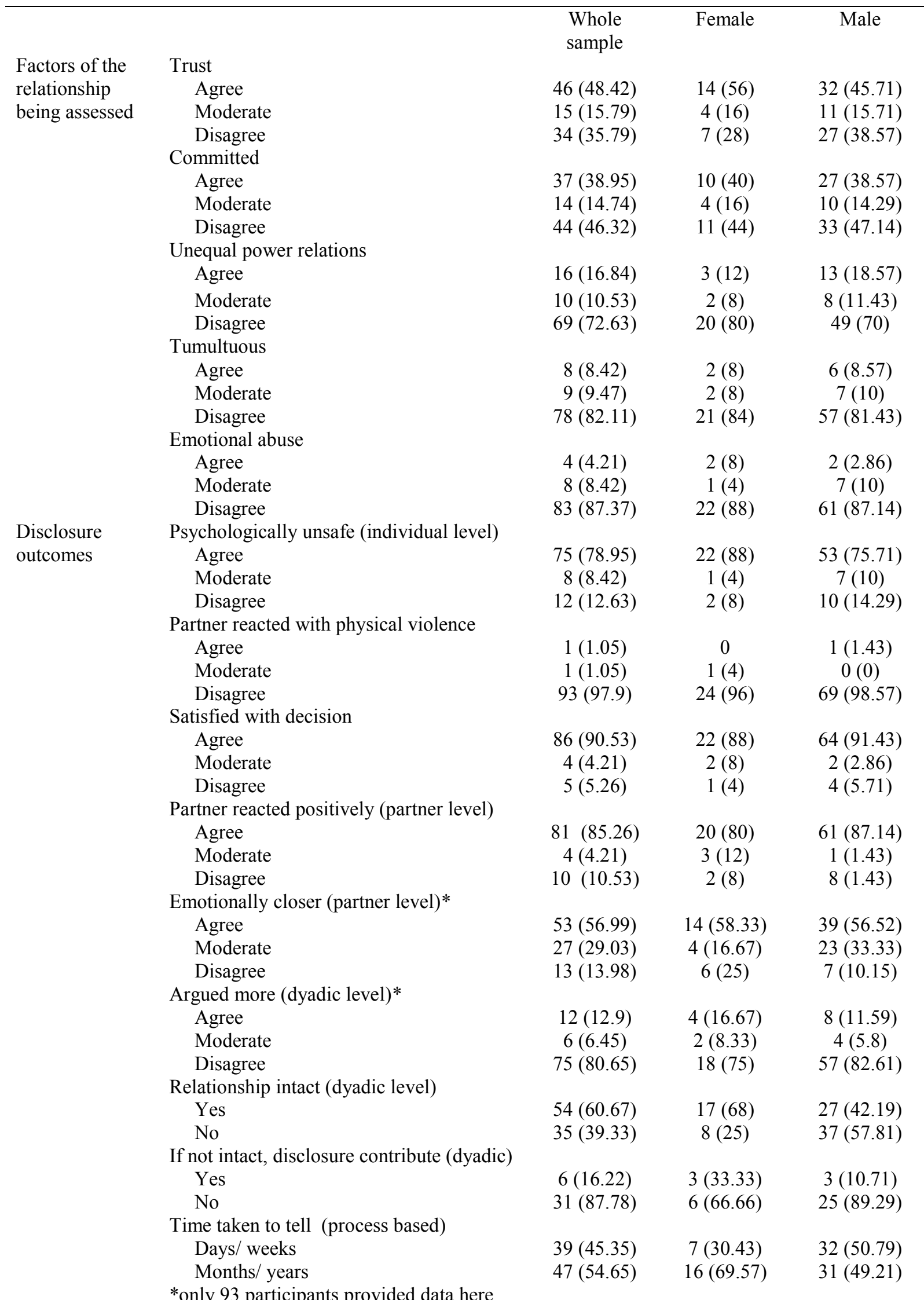


Table 4: Test statistic and $\mathrm{p}$ value for each examination into the association between factors of relationship quality and disclosure outcome

\begin{tabular}{|c|c|c|c|c|c|c|c|c|c|c|c|c|c|c|c|c|}
\hline \multirow{4}{*}{\begin{tabular}{|l|} 
\\
$\begin{array}{l}\text { Pre-disclosure } \\
\text { factors of } \\
\text { relationship quality }\end{array}$ \\
\end{tabular}} & \multicolumn{16}{|c|}{ Disclosure outcomes assessed $(\mathrm{N}=95)$} \\
\hline & \multicolumn{4}{|c|}{ Block 1: Individual level } & \multirow{2}{*}{\multicolumn{2}{|c|}{$\begin{array}{c}\text { Block 2: Partner } \\
\text { Level } \\
\text { The partner } \\
\text { reacted positively } \\
\text { immediately } \\
\text { following the } \\
\text { disclosure }\end{array}$}} & \multicolumn{8}{|c|}{ Block 3: Dyadic level } & \multirow{2}{*}{\multicolumn{2}{|c|}{$\begin{array}{c}\begin{array}{c}\text { Block 4: Process } \\
\text { level }\end{array} \\
\text { Time taken to tell }\end{array}$}} \\
\hline & \multicolumn{2}{|c|}{$\begin{array}{c}\text { Felt satisfied } \\
\text { with the decision } \\
\text { to tell }\end{array}$} & \multicolumn{2}{|c|}{$\begin{array}{c}\text { Felt } \\
\text { psychologically } \\
\text { unsafe after } \\
\text { disclosing }\end{array}$} & & & \multicolumn{2}{|c|}{$\begin{array}{c}\text { The couple } \\
\text { argued more } \\
\text { after disclosure } \\
\text { than before it }\end{array}$} & \multicolumn{2}{|c|}{$\begin{array}{l}\text { The couple were } \\
\text { more emotionally } \\
\text { close after the } \\
\text { disclosure }\end{array}$} & \multicolumn{2}{|c|}{$\begin{array}{l}\text { The relationship } \\
\text { was intact at the } \\
\text { time of completing } \\
\text { the survey }\end{array}$} & \multicolumn{2}{|c|}{$\begin{array}{c}\text { Disclosure } \\
\text { contributed to a } \\
\text { subsequent } \\
\text { break-up }\end{array}$} & & \\
\hline & $\mathrm{r}$ & $\mathrm{p}$ & $\mathrm{r}$ & $\mathrm{p}$ & $\mathrm{r}$ & $\mathrm{p}$ & $\mathrm{r}$ & $\mathrm{p}$ & $\mathrm{r}$ & $\mathrm{p}$ & $\mathrm{X}^{2}$ & $\mathrm{p}$ & $\mathrm{X}^{2}$ & $\mathrm{p}$ & $\mathrm{X}^{2}$ & $\mathrm{p}$ \\
\hline $\begin{array}{l}\text { Level of } \\
\text { commitment in } \\
\text { the relationship }\end{array}$ & -.104 & .158 & .001 & .5 & .007 & .47 & .21 & .022 & -.194 & .031 & $\mathrm{NA}$ & .579 & NA & .018 & 20.128 & $<.000625^{* *}$ \\
\hline $\begin{array}{l}\text { Level of } \\
\text { inequality in the } \\
\text { relationship }\end{array}$ & -.23 & .01 & -.46 & $<.001 *$ & -.349 & $<.001 *$ & .29 & .002 & -.156 & .067 & NA & 1 & NA & .063 & NA & .511 \\
\hline $\begin{array}{l}\text { Level of trust in } \\
\text { the relationship }\end{array}$ & -.25 & .24 & .09 & .19 & .034 & .37 & .125 & .117 & -.112 & .142 & $\mathrm{NA}$ & .392 & NA & .083 & 17.542 & $<.000625^{* *}$ \\
\hline $\begin{array}{l}\text { Degree to which } \\
\text { the relationship } \\
\text { has been } \\
\text { tumultuous }\end{array}$ & -.25 & .008 & -.36 & $<.001^{*}$ & -.309 & $.001^{*}$ & .56 & $<.001^{*}$ & -.36 & $<.001^{*}$ & NA & 1 & NA & .11 & NA & .015 \\
\hline $\begin{array}{l}\text { Extent to which } \\
\text { emotional abuse } \\
\text { was an issue in } \\
\text { the relationship }\end{array}$ & -.21 & .02 & -.35 & $<.001^{*}$ & -.363 & $<.001^{*}$ & .593 & $<.001^{*}$ & -.342 & $<.001 *$ & $\mathrm{NA}$ & 1 & NA & .294 & NA & .048 \\
\hline
\end{tabular}

*Significant at the adjusted one-tailed level of $\mathrm{p}<.00125 * *$ significant at the adjusted two-tailed level of $\mathrm{p}<.000625$ 


\section{Factors of the relationship and individual level disclosure outcome}

Three factors of relationship quality emerged as significantly associated with individual level disclosure outcome: the extent to which there were unequal power relations in the relationship, the extent to which the relationship was tumultuous and the extent to which emotional abuse was an issue in the relationship. These three relationship-oriented factors were significantly associated with level of perceived psychological safety straight after disclosing. These three factors emerged as significantly related to the level of satisfaction reported regarding the decision to tell- but did not remain so once the bonferonni correction was applied (see table 4 for the magnitude of these correlations, and significance level

\section{Factors of the relationship and partner level disclosure outcome}

The same three factors of relationship quality identified as important in terms of individual level outcome emerged as significantly associated with partner level disclosure outcome also. That is, the extent to which there were unequal power relations in the relationship, the extent to which the relationship was tumultuous and the extent to which emotional abuse was an issue in the relationship were all significantly associated with the extent to which the partner reacted positively to the discloser.

\section{Factors of the relationship and relationship level disclosure outcome}

Two factors of relationship quality emerged as significantly associated with relationship level disclosure outcome. The extent to which the relationship was tumultuous prior to the disclosure and the extent to which emotional abuse was an issue in the relationship-were both associated 
with the extent to which emotional intimacy increased following the disclosure, and the extent to which disclosure was associated with an increase in arguments. The level of commitment in the relationship was also associated with these two relationship level outcomes, but did not remain so when the bonferroni correction was applied.

Further to this, the extent to which the power relations in the relationship were unequal was associated with partner level outcome in terms of the extent to which disclosure was associated with an increase in arguments, but did not remain so once the bonferroni correction was applied. The level of commitment in the relationship also emerged as significantly associated with whether the disclosure contributed towards a subsequent breakup- but, again, did not remain so once the bonferonni correction was applied.

\section{Factors of the relationship and the disclosure process}

Two factors of relationship quality emerged as significantly associated with the process through which the disclosure occurred. Specifically, whether the discloser agreed that their relationship was committed or not was associated with the length of time before the partner was told (between being told in days/weeks or months/years) with people who reported being in a more committed relationship tending to take longer to tell their partner. A significant association was further found between whether the individual agreed that their relationship was trusting, and the length of time taken before the partner was told (between being told in days/ weeks or months/ years) with people who reported being in a more trusting relationship tending to take longer to tell their partner. 
In addition to this, the degree to which the relationship was tumultuous and the degree to which emotional abuse was an issue in the relationship were significantly associated with time taken to tell, but did not remain so once the bonferroni correction was applied.

\section{Multivariate analysis}

A stepwise regression was undertaken to examine variance in the degree to which the couple argued more after the disclosure compared to before. Seven variables were loaded into the model using the Enter method; level of stigma in the environment (as reported by the discloser), the degree to which there were unequal power relations in the relationship, the extent to which the relationship was tumultuous before the disclosure, the extent to which emotional abuse was an issue in the relationship, catharsis, social support and disclosure self-efficacy. These additional psychosocial variables were entered into the model in order to identify the (potential) relative predictive power of the relationship level factors in relation to the more heavily researched (and well supported) psychological and social oriented factors already present in the literature (i.e. a motivation to experience catharsis, social support, stigma and self-efficacy to tell their partner). The model was able to explain $41.4 \%$ of the sample outcome variance $($ Adj. $\mathrm{R} 2=.366)$, which was found to significantly predict outcome, $\mathrm{F}(7,85)=8.575, p<.001$. Only one of the variables significantly contributed to the model. The presence of emotional abuse in the intimate relationship prior to the disclosure was related to arguing more after the disclosure than before it $(\mathrm{B}=0.543, \mathrm{t}=2.91, p=.005)$.

\section{DISCUSSION}

Our findings indicate that the quality of the relationship of an intimate partnership plays a significant role in disclosure and disclosure outcomes. This supports some previous research 
which has suggested that the quality of the relationship plays a role in disclosure outcomes [e.g. 27-29]. This study is the first to draw multiple links between the quality of the relationship and widespread disclosure outcome and it suggests the need for more research in this area. General disclosure models do not fully capture this sort of complexity of the relationship context in which disclosure occurs. Yet, given improvements in medical treatments, the interpersonal aspects of HIV disclosure are much more salient in disclosure than currently understood.

Our findings indicate that unequal power relations present in the intimate relationship were associated with lower levels of psychological safety immediately following the disclosure, and a less positive reaction from the partner being disclosed to. This supports related findings in the literature where power equality in the form of financial equality in a relationship was related to more positive disclosure outcome for women who were HIV-positive [30].

The extent to which the relationship was regarded as being tumultuous prior to the disclosure event was another factor of relationship quality that had a significant effect on the disclosure outcome. This factor appeared to have one of the most far-reaching consequences out of all 5 factors assessing the quality of the relationship in which disclosure was being introduced; spanning across the individual, partner, and relationship levels of analysis at the outcome stage. Previous research has suggested that a 'smooth relationship' has been statistically linked with disclosure occurrence [see 31, 32]. Our findings provide a more nuanced picture. A more tumultuous relationship corresponded with lower feelings of psychological safety immediately following the event, and a reduced likelihood of the partner reacting positively. Those whose relationship was less tumultuous were significantly less likely to identify the event as a cause 
for later breakups that followed. A tumultuous relationship was also associated with taking significantly longer to tell the partner.

Related to these findings, Sendo et al [32] reported that the level of disagreements within a relationship prior to testing for HIV is related to disclosure. However, Sendo et al's study looked at the effect of level of disagreement on disclosure rates, and included people who were subsequently told that they were HIV negative, as well as those being told they were HIV positive. Our findings show that difficulties in the relationship are associated with the disclosure process, not only disclosure occurrence in those who are disclosing a HIV positive status.

The level of emotional abuse reportedly present in the relationship similarly had one of the most far-reaching consequences on disclosure outcome. The more emotionally abusive the relationship was, the greater the likelihood that the partner would react negatively, and the lower the feelings of psychological safety the individual reportedly experienced immediately following the event. Although perhaps one of the most important properties of this factor was that it acted as a reliable predictor of outcome. The reported level of emotional abuse as an issue in the relationship experienced prior to the event held significant predictive power in terms of the subsequent extent to which arguments increased following the event, accounting for over $40 \%$ of the variance. This finding is of particular importance as it supports that the notion that factors assessing the nature of the relationship not only co-occur with outcome measures, but predict disclosure outcome. This is consistent with findings by Sarnquist et al [33] who found that report of emotional abuse significantly predicted disclosure occurrence. 
The level of trust shared in the relationship was found in this study to have a significant effect on disclosure outcome at the relationship level. Previous research has questioned whether this variable has an effect on disclosure decision [e.g. 34, 35] and some research studies exploring trust have linked it to disclosure decision [e.g. 27, 36, 37]. Our findings indicate that relationship trust has an influence that is more pervasive than this, affecting a range of disclosure outcomes also. A high level of trust in the relationship was associated with an increase in emotional closeness following the event. It was also associated with the discloser taking significantly longer to tell their partner.

The level of commitment in the relationship was also significantly associated with length of time taken to tell the partner, and whether the disclosure was regarded as contributing to the breakup in those whose relationships were no longer intact. For those who reported their relationships as more committed, they were significantly more likely to report having taken months or years to tell them. Whereas for those whose relationships were reportedly uncommitted, these participants were significantly more likely to only take days or weeks to tell. For those whose relationships were committed, they were significantly less likely to report that the disclosure contributed to their breakup, in the case that the couples were no longer together.

There is a firm base of evidence already existing on the role of relationship commitment in HIV disclosure. This research has showed that a highly committed relationship is associated with higher odds of disclosing a HIV positive status [e.g. 14, 15]. Our findings suggest that commitment does not only affect disclosure occurrence; but has an influence on the process of disclosure too. 
It may be reasonable to suggest that those whose relationships are more committed take significantly longer to tell because they have substantially more to lose. In a less committed relationship, receiving the news that someone an individual loves has HIV may be a 'blow' for the relationship, causing its demise [38].

Our findings have a direct implication for models of HIV disclosure. It indicates that the relationship context systematically informs the disclosure process. It is now being understood that disclosure varies as a function of the category of relationship [see 39]. But more importantly than this, our findings show that the quality of this relationship affects the process of disclosure and the disclosure outcome.

These findings in turn have clinical implications. The World Health Organization [40] has previously discussed the idea of a screening tool to identify people who are vulnerable in the disclosure process. A focus on variables measuring the quality of relationship could inform the development of such a tool. One research study suggested a disclosure intervention that works with couples to increase relationship trust, to ultimately lead to disclosure occurrence [37]; Our findings suggest that this sort of intervention may have additional benefits, such as increasing the positive trajectory of the relationship following the disclosure event.

The quality of the relationship prior to the disclosure event can act as either a risk or a resilience factor in the longitudinal disclosure process. The factors assessed here that were indicative of poor relationship dynamics (e.g. a tumultuous relationship, emotional abuse) significantly correlated with negative disclosure outcomes. Whereas the factors here assessing good relational dynamics (e.g. trust) significantly correlated with positive disclosure outcomes. In the general self-disclosure literature it has previously been found that disclosure increases 
relationship satisfaction [41]. However, this research found that the quality of the relationship may moderate the effect of disclosing.

There are limitations that need to be considered. Whilst this study aimed to explore the comprehensive disclosure process within an intimate partner context, it only recruited one member of the relationship dyad. This included only collecting data from the participants when assessing the quality of their relationship in relation to the disclosure outcome. Thus we have looked at the individual's perception of the quality of their relationship. Also, assessment of the quality of the relationship relied on retrospective recall by participants. Because of this, it is possible that the disclosure outcome influenced the ratings of relationship quality in this study. A longitudinal prospective design following the effects of disclosure on both members of the relationship as they occur in real time would address these issues and confirm the findings. Furthermore, the sample was recruited through HIV support organizations, and thus may represent a bias towards people (and their relationships) who have the relative benefit of the social support offered by the organization.

It is also important to note that the previous disclosure history of the discloser was not taken into account in this study. It is possible that the prior experience the discloser brought to the disclosure had implications for the outcome- with a higher level of experience being associated with more successful disclosure outcomes due to increased ability. This finding could be explained by the feedback loop, proposed by the DPM, and supported in the empirical literature.

Aspects of the disclosure process that were not given attention here were properties of the disclosure event itself. It is reasonable to suggest that this aspect of the disclosure event may 
mediate the link between the prior quality of the relationship and the relationship level outcomes. That is, participants whose relationships rate higher on trust and commitment may be disclosing their status in a specific way that promotes a positive and more supportive reaction from the partner.

\section{REFERENCES}

1. Chaudoir SR, Fisher JD, Simoni JM. Understanding HIV disclosure: a review and application of the disclosure processes model. Soc Sci Med. 2011; 72(10);1618-29.

2. Flowers P, Davis MDM. Understanding the biopsychosocial aspects of HIV disclosure among HIV-positive gay men in Scotland. Journal of Health Psychology. 2012; 18(5):711-724.

3. Kelly JA, Kalichman SC. Behavioral research in HIV/AIDS primary and secondary prevention: recent advances and future directions. Journal of Consulting and Clinical Psychology. 2002; 70(3): 626.

4. National AIDS Trust. HIV partner notification: a missed opportunity. London: Author. 2012.

5. Rodkjaer L, Sodemann M, Ostergaard L, Lomborg K. Disclosure decisions: HIV positive persons coping with disease-related stressors. Qual Health Res. 2011; 21(9):1249-59.

6. Hosek S, Brothers J, Lemos D, the Adolescent Medicine Trials Network for HIV/AIDS Interventions. What HIV-positive young women want from behavioral interventions: a qualitative approach. AIDS Patient Care and STDs. 2012; 26(5):291-97.

7. Black BP, Miles MS. Calculating the risks and benefits of disclosure in African women who have HIV. Journal of Obstetric Gynacologic \& Neonatal Nursing. 2002;31(6):688-97.

8. Mburu G, Hodgson I, Kalibala S, et al. Adolscent HIV disclosure in Zambia: barriers, facilitators and outcomes. J of Int AIDS Soc. 2014; 17: 1-9.

9. Vyavaharkar M, Moneyham L, Corwin S, Tavakoli A, Saunders R, Annang L. HIVdisclosure, social support, and depression among HIV-infected women living in the rural southeastern united states. AIDS Education and Prevention. 2011; 23(1): 78-90. 
10. Okareh OT, Akpa OM, Okunlola JO, Okoror TA. Management of conflicts arising from disclosure of HIV status among married women in southwest Nigeria. Health Care for Women International. 2013; 36(2):149-60.

11. Valle M, Levy J. Weighing the consequences: self-disclosure of HIV-positive status among African American injection drug users. Health Education and Behavior. 2008; 36(1):155-66.

12. Gielen AC, O'Campo P, Faden RR, Eke A. Women's disclosure of HIV status: experiences of mistreatment and violence in an urban setting. Women \& Health. 1997; 25(3):19-31.

13. Gielen AC, McDonnell KA, Burke JG, O'Campo P. Women's lives after an HIV-positive diagnosis: disclosure and violence. Maternal and Child Health Journal. 2000; 4(2):111-20.

14. Arnold EM, Rice E, Flannery D, Rotheram-Borus MJ. HIV disclosure among adults living with HIV. AIDS Care. 2008;20(1):80-92.

15. Bairan A, Taylor GAJ, Blake BJ, et al. A model of HIV disclosure: disclosure and types of social relationships. Journal of the American Academy of Nurse Practitioners. 2007;19:242250.

16. Chaudoir SR, Fisher JD. The disclosure processes model: understanding disclosure decisionmaking and post-disclosure outcomes among people living with a concealable stigmatized identity. Psychol Bull. 2010;136(2):236-56.

17. Amoran OE. Predictors of disclosure of sero-status to sexual partners among people living with HIV/AIDS in ogun state, Nigeria. Nigerian Journal of Clinical Practice. 2012;15(4):38590.

18. Osinde MO, Kakaire O, Kaye DK. Factors associated with disclosure of HIV serostatus to sexual partners of patients receiving HIV care in kabala, Uganda. International Journal of Gynecology and Obstetrics. 2012;118:61-64.

19. Vu L, Andrinopoulos K, Mathews C, et al. Disclosure of HIV status to sex partners among HIV-infected men and women in cape town, south Africa. AIDS Behav. 2012; 16:132-38.

20. Katz DA, Kiarie JN, John-Stewart GC, Richardson BA, John FN, Farquhar C. HIV testing men in the antenatal setting: understanding male non-disclosure. Int J STD AIDS.

2009;20(11):765-67. 
21. Ehrhardt, AA, Exner TM, Hoffman S et al. A gender-specific HIV/STD risk reduction intervention for women in a health care setting: Short- and long-term results of a randomized clinical trial. AIDS Care. 2002; 14:147-161.

22. Field A. Discovering statistics using IBM SPSS statistics. London: Sage. 2009

23. Mayers A. Introduction to statistics and SPSS in psychology. London: Pearson. 2013.

24. APA. Reporting standards for research in psychology. Why do we need them? What might they be? American Psychologist. 2008;63(9):839-51.

25. Faul F, Erdfelder E, Buchner A, Lang A-G. Statistical power analyses using G* power 3.1: tests for correlation and regression analyses. Behavior Research Methods. 2009;41(4):114960.

26. Clark-Carter D. Quantitative psychological research: A student's handbook. East Sussex: Psychology Press. 2004.

27. Gaskins SW, Payne PF, Sowell RL, Lewis TL, Gardner A, Parton JM. Making decisions: the process of HIV disclosure for rural African American men. Am J Mens Health. 2012;6(6):442-52.

28. Nacius LA, Levison J, Minard CG, Fasser C, Davila JA. Serodiscordance and disclosure among HIV-positive pregnant women in the southwestern united states. AIDS Patient Care and STDs. 2013;27(4):242-7.

29. Stutterheim SE, Shiripinda I, Bos AER et al. HIV status disclosure among HIV-positive African and afro-caribbean people in the Netherlands. AIDS Care. 2011;23(2):195-205.

30. Malaju MT, Alene GD. Women's expectation of partner's violence on HIV disclosure for prevention of mother to child transmission of HIV in north west Ethiopia. BMC Research Notes. 2013;6(96):2-6.

31. Seid M, Wasie B, Admassu M. Disclosure of HIV positive result to a sexual partner among adult clinical service users in kemissie district, northeast Ethiopia. African Journal of Reproductive Health. 2012;16(1):97-105.

32. Sendo EG, Cherie A, Erku TA. Disclosure experience to partner and its effect on intention to utilize prevention of mother to child transmission service among HIV positive pregnant 
women attending antenatal care in addis ababa, Ethiopia. BMC Public Health. 2013;13:76571.

33. Sarnquist C, Kang J, Moyo P et al. Intimate partner violence and HIV-infection among women in Zimbabwe: a complex interplay. Oral presentation delivered at the American Public Health Association. 2014;Retrieved from https://apha.confex.com/apha/142am/webprogram/Paper312666.html.

34. Loukid M, Abadie A, Henry E et al. Factors associated with HIV status disclosure to one's steady sexual partner in PLHIV in Morocco. J Community Health. 2014; 39:50-9.

35. Lyimo RA, Stutterheim SE, Hospers HJ, de Glee T, van der Ven A, de Bruin M. Stigma, disclosure, coping and medication adherence among people living with HIV/AIDS in northern Tanzania. AIDS Patient Care and STDs. 2014;28(2):98-105.

36. Edelman EJ, Cole CA, Richardson W, Boshnack N, Jenkins H, Rosenthal MS. Opportunities for improving partner notification for HIV: results from a community-based research study. AIDS Behav. 2014;10:1888-7.

37. Villar-Loubet OM, Bruscantini L, Shikwane M, Weiss S, Peltzer K, Jones DL. HIV disclosure, sexual negotiation and male involvement in prevention-of-mother-to-childtransmission in south Africa. Culture, Health \& Sexuality. 2013;15(3):253-68.

38. Korner H. Negotiating cultures: disclosure of HIV-positive status among people from minority ethnic communities in Sydney. 2007;9(2):137-152.

39. Dima AL, Stutterheim SE, Lyimo R, de Bruin M. Advancing methodology in the study of HIV status disclosure: the importance of considering disclosure target and intent. Soc Sci Med. 2014;108:166-74.

40. World Health Organization. Gender dimensions of HIV status disclosure to sexual partners: rates, barriers and outcomes. A review paper. Author, 2004.

41. Finkenauer C, Engles RCME, Branje SJT, Meeus W. Disclosure and relationship satisfaction in families. Journal of Marriage and Family. 2004;66(1):195-209. 